\title{
Beyond PD-1 Immunotherapy in Malignant Melanoma
}

\author{
Dominika Kwiatkowska • Piotr Kluska • Adam Reich
}

Received: January 26, 2019 / Published online: March 29, 2019

(C) The Author(s) 2019

\begin{abstract}
For many years, the standard therapy for malignant melanoma was based mainly on surgical resection. Unfortunately, this treatment is curative only in the early localized stage of this malignancy. The metastatic stage of malignant melanoma still remains a huge therapeutic challenge. Despite the many new therapeutic options that have become available over the last years, there is a constant need for safer and more effective treatment modalities. There has been a dynamic development of various anti-cancer immunotherapies directed against new molecular targets. A number of clinical trials are currently being conducted to confirm their effectiveness and safety. In this review of the literature, we summarize the contemporary knowledge on promising new immunotherapies beyond the currently available treatment options for malignant melanoma, including oncolytic immunotherapy,
\end{abstract}

Enhanced digital features To view enhanced digital features for this article go to https://doi.org/10.6084/ m9.figshare.7857098.

D. Kwiatkowska · A. Reich $(\bowtie)$

Department of Dermatology, University of Rzeszow, Rzeszów, Poland

e-mail: adi_medicalis@go2.pl

P. Kluska

Wroclaw University of Science and Technology,

Wrocław, Poland selective inhibitors of indoleamine 2,3-dioxygenease, anti-PD-(L)1 (programmed death ligand 1) drugs, immune checkpoint protein LAG-3 antibodies, inhibitors of histone deacetylase (HDAC) and inhibitors of B7-H3.

Keywords: Atezolizumab; Epacadostat; Immunotherapy; Indoximod; LAG3 inhibitors; Malignant melanoma; Oncolytic immunotherapy; Talimogene laherparepvec

\begin{tabular}{|c|c|}
\hline \multicolumn{2}{|c|}{ Abbreviations } \\
\hline $\mathrm{AE}$ & Adverse events \\
\hline BRAF & B-Raf proto-oncogene \\
\hline CTLA4 & $\begin{array}{l}\text { Cytotoxic T-lymphocyte associated } \\
\text { protein } 4\end{array}$ \\
\hline DLTs & Dose-limiting toxicities \\
\hline GM-CSF & $\begin{array}{l}\text { Granulocyte macrophage-colony- } \\
\text { stimulating factor }\end{array}$ \\
\hline HDAC & Inhibitors of histone deacetylase \\
\hline IDO1 & Indoleamine 2,3-dioxygenase 1 \\
\hline IDO2 & Indoleamine 2,3-dioxygenase 2 \\
\hline IFN- $\gamma$ & Interferon gamma \\
\hline LAG-3 & Lymphocyte activation gene 3 \\
\hline MEK & Mitogen-activated protein kinase \\
\hline ORR & Overall response rate \\
\hline PD1 & Programmed cell death protein 1 \\
\hline PDL-1 & Programmed death ligand 1 \\
\hline SAE & Serious adverse event \\
\hline T-VEC & Talimogene laherparepvec \\
\hline Tregs & Tumor-associated regulatory $\mathrm{T}$ cells \\
\hline
\end{tabular}

Abbreviations

BRAF B-Raf proto-oncogene

DLTs Dose-limiting toxicities

GM-CSF Granulocyte macrophage-colony-

HDAC Inhibitors of histone deacetylase

IDO1 Indoleamine 2,3-dioxygenase 1

IDO2 Indoleamine 2,3-dioxygenase 2

IFN- $\gamma$ Interferon gamma

LAG-3 Lymphocyte activation gene 3

MEK Mitogen-activated protein kinase

ORR Overall response rate

PD1 Programmed cell death protein 1

PDL-1 Programmed death ligand 1

SAE Serious adverse event

T-VEC Talimogene laherparepvec 


\section{INTRODUCTION}

Malignant melanoma is one of the most fatal skin tumors with a consistent increase of incidence reported over the last 3 decades [1]. The data from the World Health Organization (WHO) show that every year 132,000 new cases of this neoplasm are diagnosed around the world [2]. For years, prognosis for patients with unresectable stage III-IV tumors was poor. Responses to systemic therapy, with the exception of the small group of patients reacting well to high doses of interleukin 2 (IL-2), were unsatisfactory $[3,4]$. During the last years, significant progress has been made in the development of new targeted therapies and immunotherapies [5], which has given hope to patients with advanced stage malignant melanoma and markedly changed the future directions of progress in contemporary oncology. Although new treatments have already been introduced with many studies confirming their effectiveness, other therapeutic options are still needed for this group of patients.

In this review, we have presented current trends in the development of therapy for malignant melanoma and its future potential impact on the survival of patients with this tumor.

\section{METHODS}

For the purpose of this report, the PubMed and ClinicalTrials.gov database were searched (Fig. 1). Articles were included for analysis if they concerned the following malignant melanoma treatments: oncolytic immunotherapy (e.g., talimogene laherparepvec and other oncolytic viruses), selective inhibitors of indoleamine 2,3-dioxygenease (e.g., epacadostat, indoximod), anti-PD-(L)1 (programmed death ligand 1) (e.g., atezolizumab), immune checkpoint protein LAG-3 (lymphocyte-activation gene 3) antibodies (e.g., relatlimab, eftilagimod alpha, LAG525), selective histone deacetylase (HDAC) inhibitors (e.g., entinostat), B7H3 inhibitors (e.g., enoblituzumab) and selected combinations of the above-mentioned therapies with other medications. The research data had to be published and available before 31 December 2018. Reports were excluded if they contained a description of current standard therapy of advanced melanoma, such as: checkpoint inhibitors-anti-PD1 antibodies (nivolumab and pembrolizumab), anti-CTLA-4 (cytotoxic T-lymphocyte-associated protein 4) immunoglobulin (ipilimumab) and targeted therapy (BRAF inhibitor, MEK inhibitor) unless these therapies were used in combination with previously mentioned drugs. Additional articles were included manually during investigation of papers' references if they were found relevant for current review. This article is based on previously conducted studies and does not contain any studies with human participants or animals performed by any of the authors.

\section{Talimogene Laherparepvec and Other Oncolytic Viruses}

The development of oncolytic immunotherapy has resulted in a promising treatment strategy, which in the future could yield improvement of the overall survival of patients with metastatic or unresectable malignant melanoma $[6,7]$. Oncolytic viruses (OVs) act through selective infection and lysis of tumor cells as well as enhancement of the anti-tumor immune response [8].

Talimogene laherparepvec (T-VEC) is the first and currently the only oncolytic herpes simplex virus type 1 (HSV1) used for the treatment of inoperable stage III and IV malignant melanoma approved by the FDA (Food and Drug Administration). To prevent toxicity, which was until recently a significant limitation associated with a therapeutic viral infection, HSV1 has been genetically modified to achieve T-VEC. Inactivation of neurovirulence factor ICP34.5 resulted in increased replication of the virus in tumor cells and reduced pathogenicity through the protection of normal cells [9]. This effect is enhanced by simultaneous insertion of the US11 gene [10]. Further modification by deleting the ICP47 gene allows the presentation of an antigen that has previously been inhibited by the virus [11]. T-VEC also has the ability to express GM-CSF, which potentially augments 


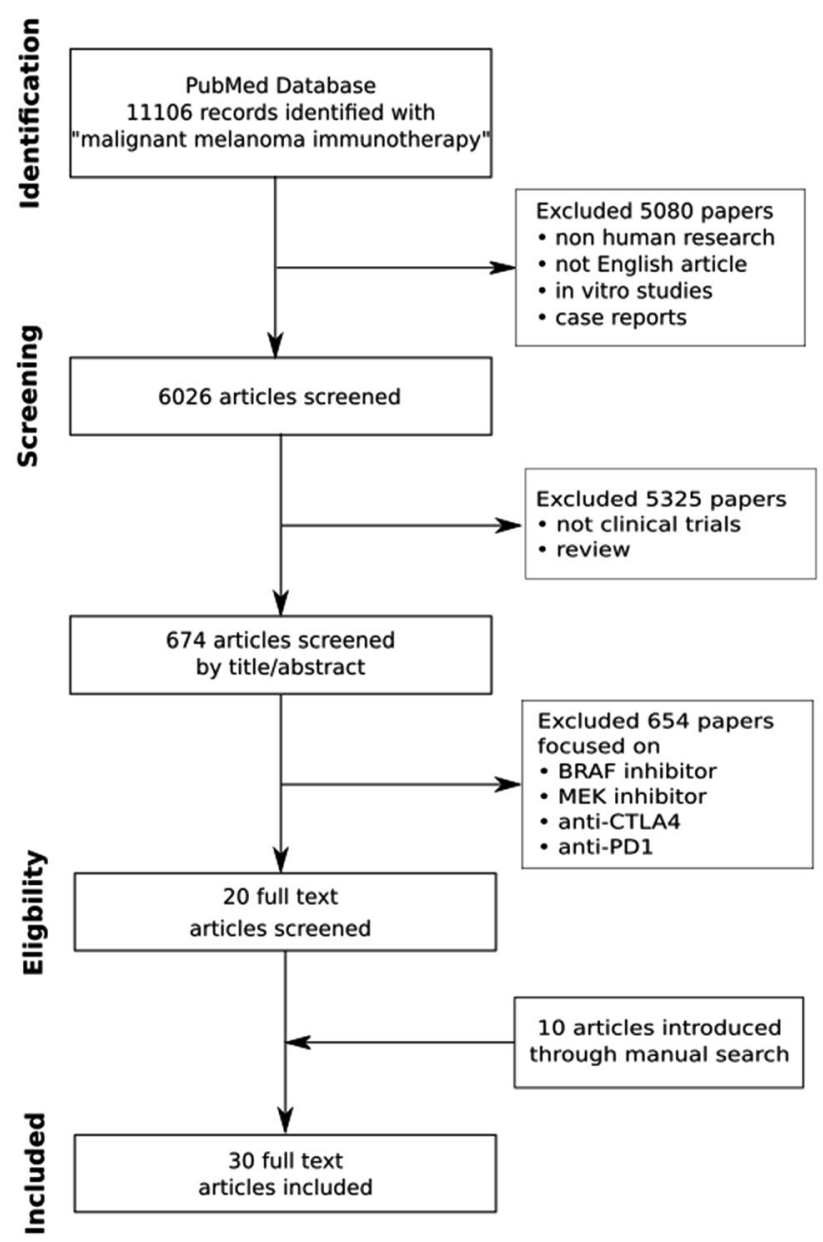

Fig. 1 Process of searching the PubMed database (BRAF B-Raf proto-oncogene, $M E K$ mitogen-activated protein kinase, PD1 programmed cell death protein 1, CTLA4 cytotoxic T-lymphocyte associated protein 4)

the systemic T-cell immune response of the host to neoplasm cells [12].

As mentioned above, the T-VEC mode of action is defined by two mechanisms: selective infection and termination of tumor cells as well as the induction of local and distant anti-tumor host immunity. In studies carried out by Kaufman et al. in patients with unresectable stage IIIc and IV metastatic melanoma, it was found that injected melanoma lesions showed an increase of MART-1 (melanoma-associated antigen recognized by $\mathrm{T}$ cells) specific CD8+ T cells and a significant decrease of suppressive immune cells [13]. It seems that these changes in the tumor microenvironment might be valid determinants of the therapeutic response.
In the randomized, open-label, phase 3 clinical trial (OPTiM), the effectiveness of T-VEC was compared with GM-CSF on a group of 436 randomly assigned patients with unresected, injectable, stage IIIB-IV malignant melanoma [14]. Analysis of the durable response rate (DRR), which includes cases with complete response (CR) and partial response (PR) present for at least 6 months, showed that DRR in patients treated with T-VEC was significantly higher than in the GM-CSF group (16.3\% vs. $2.1 \%$, respectively). Based on this study, the FDA approved T-VEC for advanced malignant melanoma.

There is a possibility of combining OVs with chemotherapy, radiation therapy, targeted therapy or immunotherapy. Strategies of 
combination therapy could potentially revolutionize and widen the spectrum of available treatment options for patients with advanced malignant melanoma. The first randomized study with the aim to check the efficacy of T-VEC with and without an anti-CTLA-4 antibody, ipilimumab, revealed that the objective response rate was higher for simultaneous treatment compared with monotherapy [15].

Furthermore, a multicenter phase 1B study (MASTERKEY-265) investigating the safety and tolerability of T-VEC with pembrolizumab in patients with stage IIIB-IV malignant melanoma also showed that combined treatment is associated with a clinical benefit [16]. The subsequent randomized, double-blind phase 3 trial (KEYNOTE-034) evaluating T-VEC (versus T-VEC-placebo) plus pembrolizumab is ongoing, and the results are not available yet [17].

There are also attempts to use T-VEC as a neoadjuvant therapy. The phase 2 study aimed to examine 150 patients with stage IIIB-IVM1a tumors before resection to evaluate the effectiveness of T-VEC treatment combined with surgical treatment compared with surgery alone. The results of this analysis have not yet been published [18].

Currently, ongoing clinical trials evaluate several other OVs in the treatment of malignant melanoma including adenoviruses, Coxsackie viruses, reoviruses, polio viruses, measles virus, vesicular stomatitis virus, vaccinia virus, Sendai virus, Newcastle disease virus (NVD) and HSV1 [19]. Although the number of the ever-tested OVs is high, in Table 1 we present those that probably should gain more clinical attention.

\section{Indoleamine-2,3-dioxygenase (IDO) Inhibitors}

Selective inhibitors of indoleamine 2,3-dioxygenease (IDO) may be effective for the treatment of advanced and metastatic melanoma. IDO is a catabolic enzyme responsible for oxidation of tryptophan to $\mathrm{N}$-formyl-kynurenine [20]. Overexpression of this rate-limiting enzyme by malignant cells is involved in immune modulation because of its ability to inhibit T-cell immune responses and consequent tumor outgrowth. Overexpression of IDO is usually associated with a worse prognosis; thus, IDO is a promising therapeutic target, and the use of its inhibitors could significantly reduce cancer neovascularization and decrease the prevalence of metastasis. Presently, preclinical and clinical trials are underway for several IDO inhibitors [21]. In Table 2, we presented selected studies focused on IDO inhibitors as well as their combinations with other treatments for malignant melanoma.

Epacadostat (INCB024360) is a novel selective inhibitor of IDO1 with good oral bioavailability. A phase 1 dose-escalation study involving 52 participants with advanced malignancies was performed to determine the safety of epacadostat. The most common side effects were abdominal pain, fatigue and hypokalemia, including grade 3 and 4 adverse events. The study also identified $600 \mathrm{mg}$ epacadostat as the recommended dose of the drug as monotherapy [22]. Nevertheless, monotherapy with IDO1 inhibitors did not show marked clinical activity; therefore, further studies are ongoing to establish the best combination of epacadostat with other immunotherapies.

In a phase $1 / 2$ randomized and placebocontrolled study, an attempt was made to combine epacadostat with ipilimumab. The 25-mg dose of epacadostat in combination with the standard dose of ipilimumab was generally well tolerated. Adverse effects were reversible with corticosteroids and discontinuation of treatment. This research allowed the conclusion that epacadostat might enhance clinical activity of ipilimumab [23].

Epacadostat has also been evaluated in combination with pembrolizumab in reference to patients with advanced melanoma and other solid tumors. A phase $1 / 2$, multicenter, nonrandomized, open-label study showed promising efficacy and durable antitumor activity. Unfortunately, phase 3 study did not meet the primary end point of improvement in PFS compared with pembrolizumab monotherapy $[24,25]$. The reasons for this negative trial remain undetermined [26]. Furthermore, other attempts were taken to assess the effectiveness of various drugs plus epacadostat, some of which are gathered in Table 2. 
Table 1 Examples of oncolytic viruses tested for malignant melanoma treatment

\begin{tabular}{|c|c|c|c|c|c|c|}
\hline $\begin{array}{l}\text { Oncolytic } \\
\text { virus }\end{array}$ & Description & $\begin{array}{l}\text { Research } \\
\text { phase }\end{array}$ & $\begin{array}{l}\text { Research } \\
\text { status }\end{array}$ & Participants & Research ID & Outcomes \\
\hline \multirow[t]{2}{*}{$\begin{array}{c}\text { Coxsackie } \\
\text { virus } \\
A 21\end{array}$} & $\begin{array}{l}\text { Multicenter, open- } \\
\text { label, phase } 2 \text { study } \\
\text { in patients with stage } \\
\text { IIIc and IV } \\
\text { malignant melanoma }\end{array}$ & Phase 2 & Completed & 57 & NCT01227551 & $\begin{array}{l}\text { ORR rate was } 28.1 \% \\
\text { Grade } 1 \text { AEs included: } \\
\text { fatigue, chills, local } \\
\text { injection site } \\
\text { reactions and fever } \\
\text { No grade } 3 \text { or } 4 \text { AEs } \\
\text { were observed }\end{array}$ \\
\hline & $\begin{array}{l}\text { Phase } 2 \text { study in } \\
\text { patients with stage } \\
\text { IIIc-IV malignant } \\
\text { melanoma to extend } \\
\text { dosing for up to } \\
48 \text { weeks }\end{array}$ & Phase 2 & Completed & 16 & NCT01636882 & $\begin{array}{l}\text { CVA21 treatment } \\
\text { increased immune } \\
\text { cell infiltrates } \\
(\text { CD3 }+ \text { CD8 ) and } \\
\text { expression of PD-L1 } \\
\text { SAEs and AEs were } \\
\text { irrespective of } \\
\text { treatment }\end{array}$ \\
\hline Adenovirus & $\begin{array}{l}\text { Phase } 1 / 2 \text {, single-arm } \\
\text { study of } \\
\text { intratumoral } \\
\text { injections in patients } \\
\text { with inoperable stage } \\
\text { III-IV melanoma }\end{array}$ & Phase $1 / 2$ & Completed & 14 & NCT01397708 & $\begin{array}{l}\text { Treatment was well } \\
\text { tolerated and } \\
\text { induced biologic and } \\
\text { clinical activity. } \\
\text { AEs included chills } \\
\text { (78.6\%), pyrexia } \\
(78.6 \%) \text {, fatigue } \\
(71.4 \%) \text { and nausea } \\
(71.4 \%)\end{array}$ \\
\hline $\begin{array}{l}\text { ECHO } 7 \\
\quad \text { virus } \\
\quad\left(\text { Rigvir }^{\circledR}\right)\end{array}$ & $\begin{array}{l}\text { A retrospective study } \\
\text { to determine the } \\
\text { efficacy of Rigvir }{ }^{\circledR} \text { in } \\
\text { patients with IB-IIC } \\
\text { malignant melanoma }\end{array}$ & $\begin{array}{l}\text { Registered } \\
\text { in Latvia }\end{array}$ & $\begin{array}{l}\text { Not } \\
\text { applicable }\end{array}$ & 79 & PMC4560272 & $\begin{array}{l}\text { Rigvir }^{\circledR} \text { extended } \\
\text { survival in patients } \\
\text { with malignant } \\
\text { melanoma } \\
\text { AEs }>\text { class } 2 \text { were } \\
\text { absent }\end{array}$ \\
\hline HF10 & $\begin{array}{l}\text { Phase 1, open-label } \\
\text { multicenter study, } \\
\text { evaluating } \\
\text { intratumoral } \\
\text { injections of the } \\
\text { HF10 in refractory } \\
\text { and superficial } \\
\text { lesions (including } \\
\text { malignant } \\
\text { melanoma) }\end{array}$ & Phase 1 & Completed & 28 & NCT01017185 & $\begin{array}{l}\text { Six patients had AEs } \\
\text { associated with } \\
\text { HF10, including } \\
\text { chills (two patients) } \\
\text { and discolorations at } \\
\text { the injection site, } \\
\text { edema and pain, } \\
\text { malaise, pruritus and } \\
\text { hypotension (one } \\
\text { patient each) }\end{array}$ \\
\hline
\end{tabular}

$O R R$ overall response rate, $A E s$ adverse events, $S A E s$ serious adverse events 


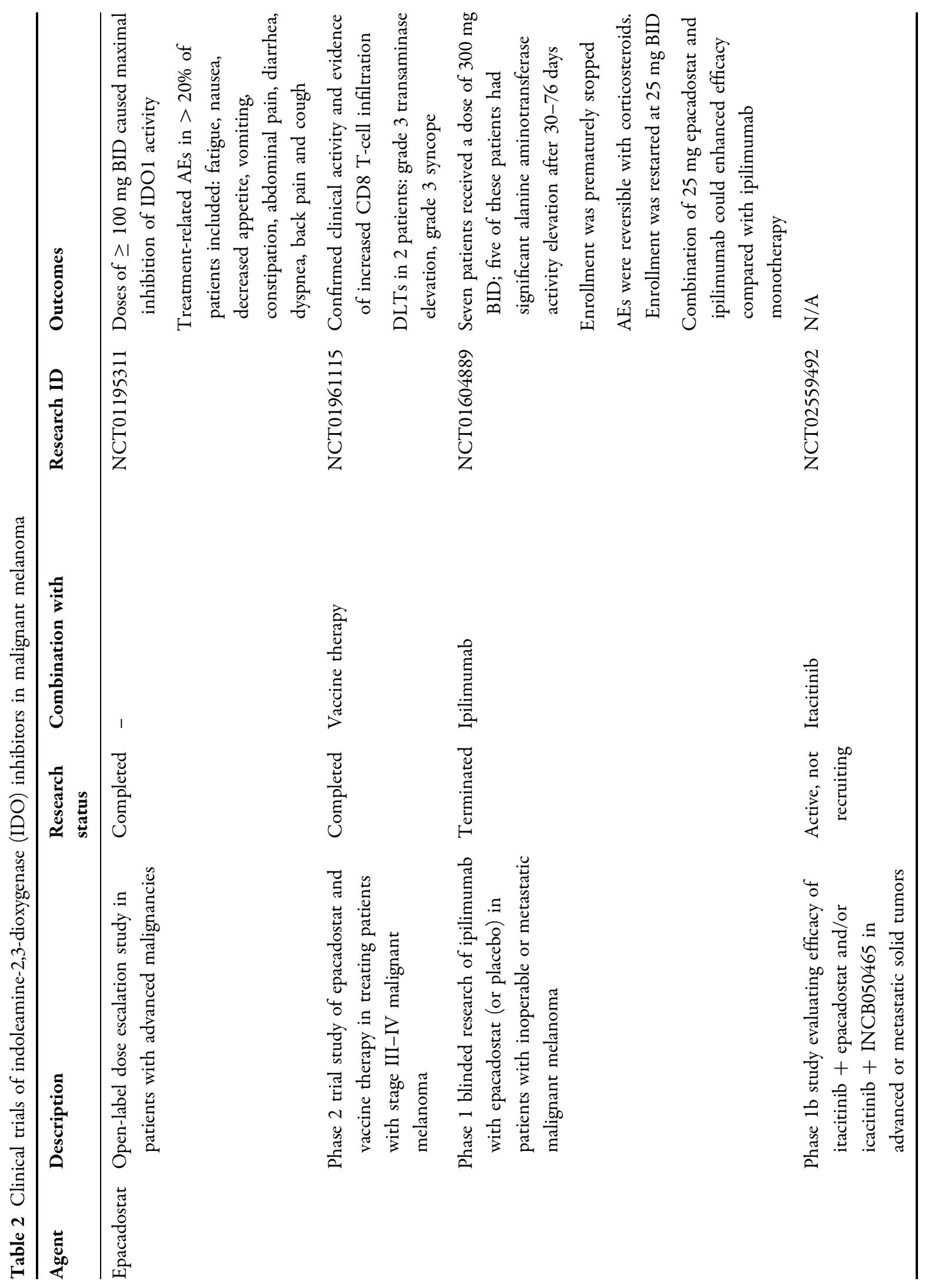




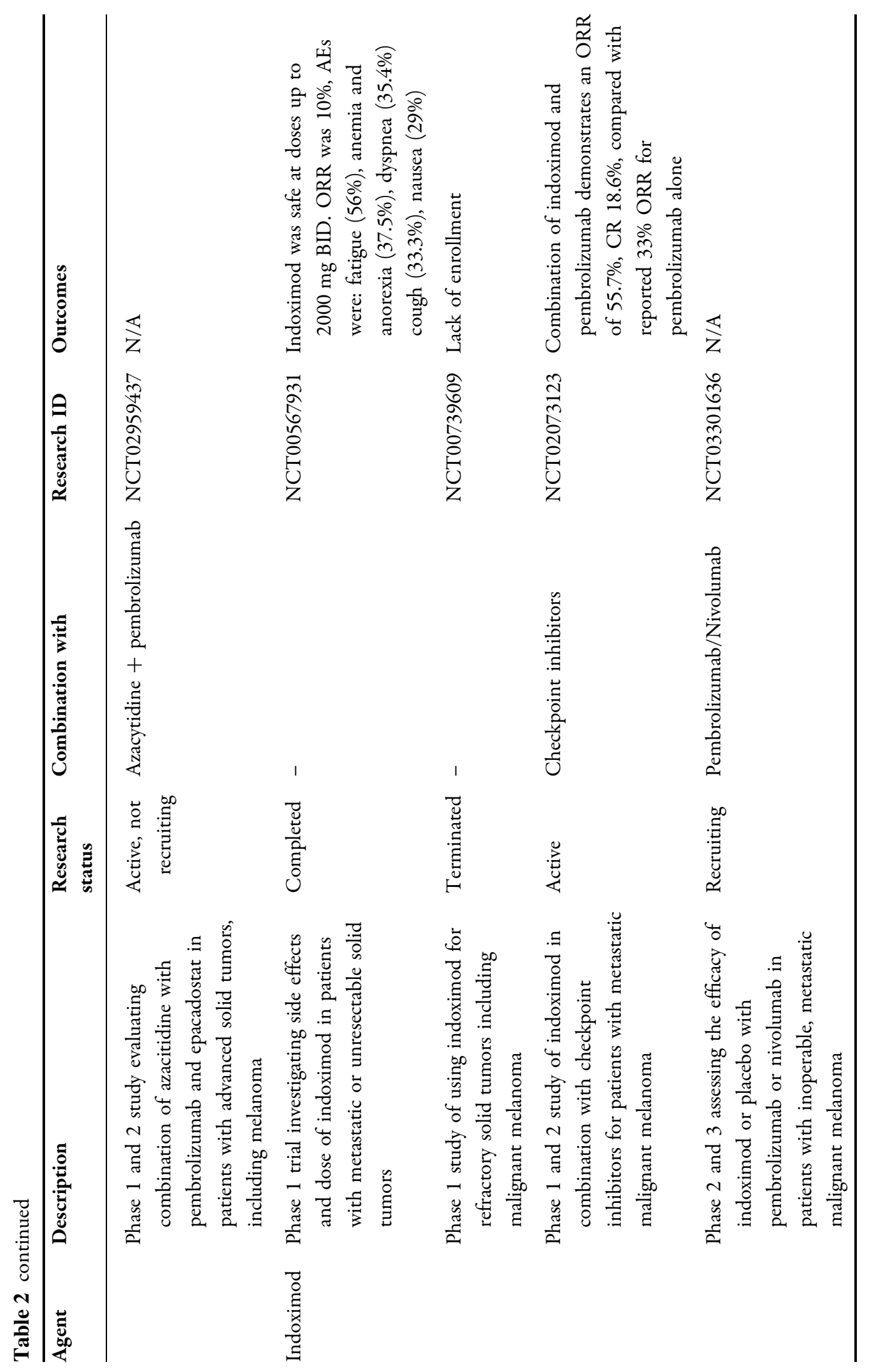







Indoximod (D-1-methyl-tryptophan) is an orally available, indirect inhibitor of IDO1 and also a more selective IDO2 inhibitor of the indoleamine 2,3-dioxygenase pathway. Indoximod showed anti-tumor activity and synergistic action with various chemotherapeutics. The primary end point in the phase 1 study was to determine the maximal well-tolerated dose (MTD) in 48 patients with advanced malignancies. The dose ranged from $200 \mathrm{mg}$ once a day to $2000 \mathrm{mg}$ twice daily. Unfortunately, MTD has not been reached, but no significant increase in toxicity was observed between various doses, and no patients stopped treatment because of any toxicity. The authors concluded that indoximod was generally well tolerated [27]. As in the case of epacadostat, antitumor activity of monotherapy with indoximod was unsatisfactory, and many combinations with other immunotherapies are being investigated (Table 2).

The ineffectiveness of the IDO inhibitor as monotherapy can be associated with immune evasion of TRCs that lead to tumor recurrence, drug resistance and formation of metastasis. TRCs are self-renewing cancer cells similar to stem cells with the ability to repopulate tumors. Nonetheless, the combination of IFN- $\gamma$ with IDO1 inhibitors is currently the only therapy that could potentially eliminate TRCs and thus may improve treatment outcomes. Given the TRC dormancy that was induced by IFN- $\gamma$ and immunosuppression caused by IDO1, TRCs are vulnerable to attacks by T cells and NK cells, which makes this strategy of immunotherapy very promising [28].

\section{Anti-PD-(L)1-Programmed Death Ligand 1}

Expression of an immune-checkpoint proteinPD-L1 on the surface of tumor cells could restrain T-cell function. PD-L1 binds to the PD-1 and B7.1 proteins. The PD-1/PD-L signaling pathway is one of the key mechanisms that could contribute to the inhibition of the antitumor response and thus protect tumor cells. The respective components of the PD-1/PD-L pathway are targets of immunotherapy with specific monoclonal antibodies. One of them is atezolizumab-an engineered humanized monoclonal anti-PD-L1 antibody [29].

Monotherapy with atezolizumab will be investigated in a phase $1 \mathrm{~b}$ study (NCT03178851) with the following evaluation criteria: the efficacy, safety and pharmacokinetics of this drug in patients with BRAFV600WT metastatic malignant melanoma who have not been previously treated. This study will also assess the combination of cobimetinib and atezolizumab in patients who have worsened despite anti-PD-1 therapy.

Recent studies have shown that atezolizumab can act synergistically with MEK inhibitors, such as cobimetinib [30]. Thus, it might be a potential therapeutic option for patients with metastatic malignant melanoma. Unfortunately, this combination has not been licensed yet for any indication in the EU. The phase 3, multicenter, randomized trial (NCT03273153) intended to measure the efficacy and safety of cobimetinib plus atezolizumab compared with pembrolizumab in previously untreated participants with advanced wild-type BRAFV600 melanoma. This study is currently in a recruitment phase. There have also been attempts to combine atezolizumab with cobimetinib and vemurafenib. Updated results confirm the preliminary data, which have shown a manageable safety profile $[31,32]$. Continued investigation of this combination is justified.

\section{LAG3 inhibitors}

Tumors have the ability to escape immune surveillance, and detailed knowledge of these mechanisms led to discoveries that signaling via specific receptors, such as LAG3 or PD1, could cause T-cell dysfunction [33]. The first results of a clinical trial have shown that the concomitant usage of immune checkpoint protein LAG-3 antibodies, relatlimab and nivolumab, to increase the anti-tumor immunity by restoring the activation of $T$ cells is safe and effective for patients who have progressed despite targeted immunotherapy. ORR was $11.5 \%$; one patient achieved a complete response, and six had partial responses. In patients with LAG-3 
expression $\geq 1 \%$, ORR was higher. In this study, $4.4 \%$ of patients had one or more AEs in grade 3 or 4 associated with the treatment, and 1.5\% had to stop the treatment because of AE [34].

Under investigation is also IMP321-eftilagimod alpha, the first class MHC-II agonist that could potentially be used with other drugs. Phase 1 study (NCT02676869) of IMP321 in combination with pembrolizumab was performed to determine the safety, tolerability and recommended dose for phase 2 study on patients with stage III and IV malignant melanoma.

Moreover, another monoclonal antibody, LAG525, is currently being tested in a phase $1 / 2$ clinical trial (NCT02460224). The main purpose of the study is to assess the safety, tolerability, pharmacokinetics (PK), pharmacodynamics (PD) and antitumor activity of LAG525 alone or with PDR001 (new anti-PD1 compound) in adult patients with solid tumors.

\section{Inhibitors of Histone Deacetylase (HDAC) and $\mathrm{B} 7-\mathrm{H} 3$}

Another promising therapy for patients who suffer from malignant melanoma unequivocally resistant to prior anti-PD-(L) 1 treatment is the simultaneous administration of a class I selective histone deacetylase (HDAC) inhibitor, entinostat, with pembrolizumab. The purpose of this combination is to reinforce inflammation in the neoplasm microenvironment required for propitiously retreatment with an anti-PD(L)1. In a phase $1 \mathrm{~b} / 2$ study, the predominant treatment-related AEs were nausea, fatigue, diarrhea and pruritus. Updated results confirm preliminary findings that entinostat plus pembrolizumab have a manageable safety profile [35].

Furthermore, patients with B7-H3-expressing melanoma have been enrolled in a phase 1 study whose aim is to evaluate the safety of enoblituzumab (MGA271) with pembrolizumab. Enoblituzumab is a monoclonal antibody that has the ability to bind to B7-H3 (CD276). B7-H3 overexpression has been shown in many tumors, including melanoma; unfortunately, it is also associated with poor prognosis. On the other hand, B7-H3 shows limited expression in normal tissue, which may help to reduce the risk of AEs associated with autoimmunity. The NCT02475213 trial (a dose escalation, open-label and cohort expansion study) focuses on the evaluation of targeting both receptors, B7-H3 and PD-1, in patients with advanced B7-H3-expressing cancers [36].

\section{Future Directions}

In our article, we have summarized a number of different treatment strategies currently under development for malignant melanoma. However, there are many unanswered questions that need to be addressed in the near future.

Regarding oncolytic viruses, future studies should focus on new potential combinations with other treatment modalities. Besides clinical trials evaluating combination with immune T-cell checkpoint inhibitors targeting CTLA-4 or PD-1, special attention should be given to a combination of available oncolytic virotherapies with radiation therapy, BRAF inhibitors, MEK inhibitors or adaptive T-cell therapy. Moreover, further investigations might evaluate the application of oncolytic viruses not only in melanoma therapy, but also in other skin tumors that are easily accessible for injections, such as Merkle cell tumors, squamous cell carcinoma or basal cell carcinoma. Studies should also focus on better understanding of the mechanisms underlying the anti-cancer immune response mediated by oncolytic viruses and on the assessment of prognostic biomarkers of therapeutic response; these are crucial for the proper identification of patients who could benefit from this type of therapy. This could also enable a better selection of patients for clinical trials and might help to reduce unnecessary expenses while such therapy is being approved for use.

Monotherapies do not always bring the desired results, as in the case of IDO inhibitors. However, combined therapies create the opportunity to widen the therapeutic window. IDO2 inhibitors could limit autoimmune-related adverse events caused by other cancer therapies. There is also quite strong evidence of 


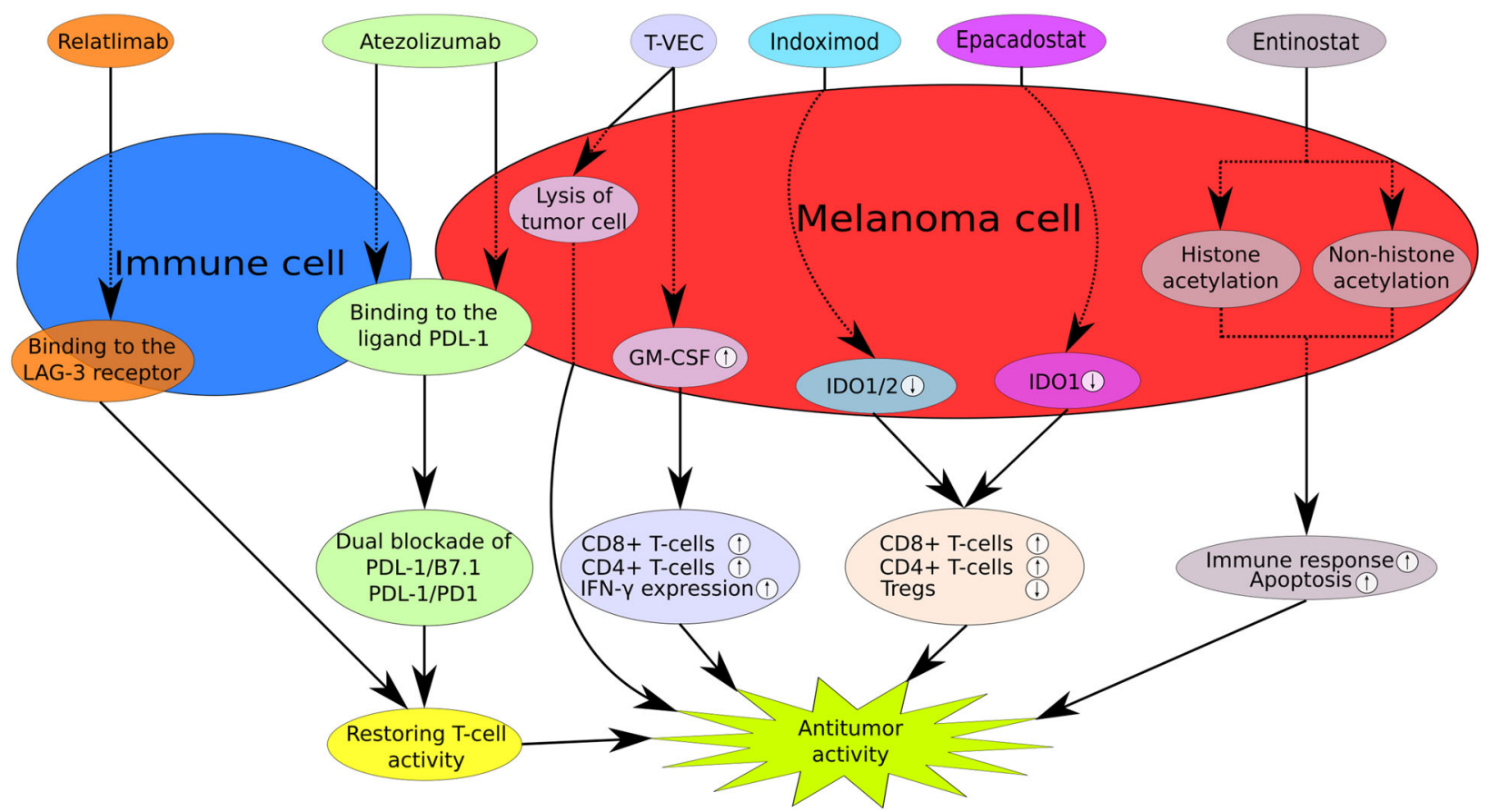

Fig. 2 Overview of action mechanisms of selected drugs that are under development for malignant melanoma therapy: (from left to right) relatlimab, a monoclonal antibody, binds to the LAG3 receptor, which is present on the surface of specialized immune cells, restoring its activity and allowing them to attack cancer cells; atezolizumab, a monoclonal antibody, binds to the PD-L1 on both tumor cells and immune cells, blocking its interactions with PD1 and $\mathrm{B} 7.1$ receptors and restoring $\mathrm{T}$-cell activity; T-VEC presents a dual mechanism of action-selective viral replication results in lysis of tumor cells and production of GM-CSF by tumor cells upon T-VEC further leads to proliferation of CD4+ and CD8 + T-cell and IFN- $\gamma$ expression; indoximod downregulates the IDO pathway, resulting in the immunostimulatory effect of $\mathrm{CD} 4+$ and

the interaction among CTLA-4, PD-L1 and IDO. Holmgaard et al. have shown that IDO expression has an inhibitory role in both anti-CTLA-4 and anti-PD1/PD-L1 therapies [37]. Despite so far unsuccessful clinical trials, investigation of the effect of IDO inhibitors, as part of combination strategies in malignant melanoma patients, is essential and should be further studied.

As in the case of many other immunotherapies, blockade of PD-L1 presented beneficial effects only in a subgroup of patients. The latest studies have shown that the efficacy of PD-L1
CD8 + T cells and a decrease of Tregs; epacadostat inhibits the IDO1 enzyme, which leads to the restoration of CD8+ T-cell and CD4+ T-cell proliferation and a reduction of Tregs; entinostat works through the epigenetic mechanism of action involving histone acetylation and simultaneous acetylation of non-histone proteinsthis dual mechanism causes an increase of the immune response and melanoma cell apoptosis (T-VEC talimogene laherparepvec, $L A G-3$ lymphocyte activation gene 3, $P D L$ 1 programmed death ligand $1, P D 1$ programmed cell death protein 1, GM-CSF granulocyte macrophage-colony-stimulating factor, IDO1 indoleamine 2,3-dioxygenase 1, IDO2 indoleamine 2,3-dioxygenase $2, I F N-\gamma$ interferon gamma; Tregs tumor-associated regulatory $\mathrm{T}$ cells)

therapy could be improved by modulation of gut microbiota [38]. Increased anti-PD-L1 efficacy was observed in mouse models after administration of Bifidobacterium [39]. Future studies should concentrate on investigations of the molecular mechanisms of this action. Finally, the question of whether chronic infection or inflammation could impact the effectiveness of the PD-L1 blockade arises.

Furthermore, the current studies did not fully disclose the exact function of LAG-3. Comprehensive understanding of this action might have a tremendous impact on the 
Table 3 Summary of different immunotherapies being currently developed

\begin{tabular}{|c|c|c|c|}
\hline Drug & Mechanism of action & Comments & References \\
\hline Atezolizumab & $\begin{array}{l}\text { Binding to the PD-L1 and further } \\
\text { blocking its interaction with PD1 and } \\
\text { B7.1 } \\
\text { Restoring T-cell activity }\end{array}$ & $\begin{array}{l}\text { Atezolizumab can act synergistically with } \\
\text { MEK inhibitors } \\
\text { Continued investigation of this drug in } \\
\text { combination with other } \\
\text { immunotherapies is required }\end{array}$ & [29-32] \\
\hline Enoblituzumab & $\begin{array}{l}\text { Direct binding to } \mathrm{B} 7-\mathrm{H} 3 \text { over-expressed } \\
\text { on tumor cells and cancer stem-like cells }\end{array}$ & $\begin{array}{l}\text { The drug is currently being tested in } \\
\text { combination with pembrolizumab for } \\
\text { patients with B7-H3-expressing } \\
\text { melanoma }\end{array}$ & $\begin{array}{l}\text { NCT02475213 } \\
\text { trial }\end{array}$ \\
\hline Entinostat & $\begin{array}{l}\text { Histone and non-histone acetylation. } \\
\text { Increase of immune response and } \\
\text { apoptosis }\end{array}$ & $\begin{array}{l}\text { Entinostat plus pembrolizumab achieved } \\
\text { manageable safety profile } \\
\text { Reinforcing of inflammation in the } \\
\text { neoplasm microenvironment could } \\
\text { improve retreatment with an anti-PD- } \\
\text { L1 in patients with malignant melanoma }\end{array}$ & {$[35]$} \\
\hline Epacadostat & $\begin{array}{l}\text { Selective inhibition of IDO1 resulting in } \\
\text { restoration of } \mathrm{CD} 8+\mathrm{T} \text { cells, } \\
\text { proliferation of } \mathrm{CD} 4+\mathrm{T} \text { cells and } \\
\text { reduction of Tregs }\end{array}$ & $\begin{array}{l}\text { Epacadostat was generally well tolerated } \\
\text { and might enhance activity of } \\
\text { ipilimumab } \\
\text { Monotherapy with epacadostat did not } \\
\text { show marked clinical activity } \\
\text { The attempt of simultaneous usage of } \\
\text { epacadostat and pembrolizumab did not } \\
\text { meet the primary end point } \\
\text { Combinations with other } \\
\text { immunotherapies are currently under } \\
\text { investigation }\end{array}$ & {$[22-26]$} \\
\hline $\begin{array}{l}\text { IMP321- } \\
\text { eftilagimod } \\
\text { alpha }\end{array}$ & $\begin{array}{l}\text { Stimulation of antigen-presenting cells } \\
\text { and induction of sustained immune } \\
\text { responses }\end{array}$ & $\begin{array}{l}\text { The addition of eftilagimod alpha might } \\
\text { improve the objective response rates as } \\
\text { compared with PD1 inhibitor } \\
\text { monotherapy } \\
\text { Clinical trials for patients with malignant } \\
\text { melanoma are still ongoing }\end{array}$ & $\begin{array}{l}\text { NCT02676869 } \\
\text { trial }\end{array}$ \\
\hline Indoximod & $\begin{array}{l}\text { Indirect suppression of IDO1 and more } \\
\text { selective inhibition of IDO2 resulting in } \\
\text { an increased number of CD8+ T cells, } \\
\mathrm{CD} 4+\mathrm{T} \text { cells and a decrease of Tregs }\end{array}$ & $\begin{array}{l}\text { Indoximod was generally well tolerated } \\
\text { Antitumor activity as monotherapy was } \\
\text { unsatisfactory } \\
\text { Further investigations of combination of } \\
\text { indoximod with other immunotherapies } \\
\text { are pending }\end{array}$ & {$[27]$} \\
\hline
\end{tabular}


Table 3 continued

\begin{tabular}{|c|c|c|c|}
\hline Drug & Mechanism of action & Comments & References \\
\hline LAG525 & $\begin{array}{l}\text { Antibody-dependent cell cytotoxicity and } \\
\text { T-cell stimulation }\end{array}$ & $\begin{array}{l}\text { This monoclonal antibody is currently } \\
\text { being tested to assess its safety and } \\
\text { efficacy } \\
\text { LAG525 has potential to change the } \\
\text { tumor microenvironment to be more } \\
\text { favorable for immune response }\end{array}$ & $\begin{array}{l}\text { NCT02460224 } \\
\text { trial }\end{array}$ \\
\hline Relatlimab & $\begin{array}{l}\text { Binding to the LAG3 receptor and } \\
\text { restoring T-cell activity }\end{array}$ & $\begin{array}{l}\text { Simultaneous administration of relatlimab } \\
\text { and nivolumab was well tolerated and } \\
\text { effective } \\
\text { Safety profile was similar to nivolumab } \\
\text { monotherapy }\end{array}$ & {$[34]$} \\
\hline T-VEC & $\begin{array}{l}\text { Selective infection and lysis of tumor cells, } \\
\text { increase of GM-CSF production as well } \\
\text { as induction of local and distant tumor } \\
\text { specific immune response }\end{array}$ & $\begin{array}{l}\text { T-VEC has a favorable safety profile and } \\
\text { good efficacy in patients with } \\
\text { unresectable malignant melanoma } \\
\text { without distant metastases } \\
\text { T-VEC can also be successfully combined } \\
\text { with other immunotherapies to improve } \\
\text { their efficacy }\end{array}$ & {$[9-16]$} \\
\hline
\end{tabular}

indication of new therapeutic regimens. The heightened interest should not only concern combinatorial PD1 immunotherapy and LAG-3, but also other first-line treatment options with LAG-3 inhibitors.

\section{CONCLUSIONS}

In recent years, poor efficacy of the treatment of malignant melanoma has led to the continuation of research to better understand how to stimulate the anti-cancer immune response. As stated before, many clinical trials are still ongoing. The simplified action mechanisms of drugs that were considered in this review are presented in the Fig. 2 below, and the summary of the discussed drugs is shown in Table 3.

We hope that novel treatment modalities for advanced malignant melanoma can lead to marked changes in this neoplasm therapy and significant improvement of the survival rate of patients with malignant melanoma.

\section{ACKNOWLEDGEMENTS}

Funding. No funding or sponsorship was received for this study or publication of this article.

Authorship. All named authors meet the International Committee of Medical Journal Editors (ICMJE) criteria for authorship for this article, take responsibility for the integrity of the work as a whole, and have given their approval for this version to be published.

Disclosures. Adam Reich has worked as a Consultant or Speaker for AbbVie, Bioderma, Celgene, Chema Elektromet, Eli Lilly, Galderma, Janssen, Leo Pharma, Medac, Menlo Therapeutics, Novartis, Pierre-Fabre and Trevi and participated as Principal Investigator or Subinvestigator in clinical trials sponsored by AbbVie, Drug Delivery Solutions Ltd, Galderma, Janssen, Kymab Limited, Leo Pharma, Menlo 
Therapeutics, MetrioPharm, MSD, Novartis and Trevi. Piotr Kluska and Dominika Kwiatkowska have nothing to disclose.

Compliance with Ethics Guidelines. This article is based on previously conducted studies and does not contain any studies with human participants or animals performed by any of the authors.

Data Availability. Data sharing is not applicable to this article as no data sets were generated or analyzed during the current study.

Open Access. This article is distributed under the terms of the Creative Commons Attribution-NonCommercial 4.0 International License (http://creativecommons.org/licenses/ by-nc/4.0/), which permits any noncommercial use, distribution, and reproduction in any medium, provided you give appropriate credit to the original author(s) and the source, provide a link to the Creative Commons license, and indicate if changes were made.

\section{REFERENCES}

1. American Cancer Society. Key statistics for melanoma skin cancer. https://www.cancer.org/cancer/ melanoma-skin-cancer/about/key-statistics.html\# references. Accessed 23 Oct 2018.

2. World Health Organization. Skin cancers. http:// www.who.int/uv/faq/skincancer/en/index1.html. Accessed 23 Oct 2018.

3. Agarwala SS. Current systemic therapy for metastatic melanoma. Exp Rev Anticancer Ther. 2009;9:587-95.

4. Radny P, Caroli UM, Bauer J. Phase II trial of intralesional therapy with interleukin-2 in soft-tissue melanoma metastases. $\mathrm{Br} \mathrm{J}$ Cancer. 2003;89:1620-6.

5. Lau PKH, Ascierto PA, McArthur G. Melanoma: the intersection of molecular targeted therapy and immune checkpoint inhibition. Curr Opin Immunol. 2016;39:30-8.

6. Hoffner B, Iodice GM, Gasal E. Administration and handling of talimogene laherparepvec: an intralesional oncolytic immunotherapy for melanoma. Oncol Nurs Forum. 2016;43:219-26.
7. Alberts P, Tilgase A, Rasa A, Bandere K, Venskus D. The advent of oncolytic virotherapy in oncology: the Rigvir $^{\circledR}$ story. Eur J Pharmacol. 2018;837:117-26.

8. Bayan C-AY, Lopez AT, Gartrell RD, et al. The role of oncolytic viruses in the treatment of melanoma. Curr Oncol Rep. 2018;20:80.

9. Liu BL, Robinson M, Han ZQ, et al. ICP34. 5 deleted herpes simplex virus with enhanced oncolytic, immune stimulating, and anti-tumour properties. Gene Ther. 2003;10:292-303.

10. Poppers J, Mulvey M, Khoo D, Mohr I. Inhibition of PKR activation by the proline-rich RNA binding domain of the herpes simplex virus type 1 Us 11 protein. J Virol. 2000;74:11215-21.

11. He B, Chou J, Brandimarti R, Mohr I, Gluzman Y, Roizman B. Suppression of the phenotype of gamma (1) 34.5-herpes simplex virus 1: failure of activated RNA-dependent protein kinase to shut off protein synthesis is associated with a deletion in the domain of the alpha47 gene. J Virol. 1997;71:6049-54.

12. Kohlhapp FJ, Kaufman HL. Molecular pathways: mechanism of action for talimogene laherparepvec, a new oncolytic virus immunotherapy. Clin Cancer Res. 2016;22:1048-54.

13. Kaufman HL, Kim DW, Deraffele G, Mitcham J, Coffin RS, Kim-Schulze S. Local and distant immunity induced by intralesional vaccination with an oncolytic herpes virus encoding GM-CSF in patients with stage IIIc and IV melanoma. Ann Surg Oncol. 2010;17:718-30.

14. Andtbacka RHI, Kaufman HL, Collichio F, et al. Talimogene laherparepvec improves durable response rate in patients with advanced melanoma. J Clin Oncol. 2015;33:2780-8.

15. Chesney J, Puzanov I, Collichio F, et al. Randomized, open-label phase II study evaluating the efficacy and safety of talimogene laherparepvec in combination with ipilimumab versus ipilimumab alone in patients with advanced, unresectable melanoma. J Clin Oncol. 2018;36:1658-67.

16. Long G, Dummer R, Ribas A, Puzanov I, Walde A. Efficacy analysis of MASTERKEY-265 phase $1 \mathrm{~b}$ study of talimogene laherparepvec (T-VEC) and pembrolizumab (pembro) for unresectable stage IIIB-IV melanoma. J Clin Oncol. 2016;34(Suppl. 15):9568.

17. Pembrolizumab with or without talimogene laherparepvec or talimogene laherparepvec placebo in unresected melanoma (KEYNOTE-034). https:// clinicaltrials.gov/ct2/show/NCT02263508. Accessed 29 Oct 2018 
18. Andtbacka RHI, Chastain M, Li A, Shilkrut M, Ross MI. Phase 2, multicenter, randomized, open-label trial assessing efficacy and safety of talimogene laherparepvec (T-VEC) neoadjuvant treatment (tx) plus surgery vs surgery for resectable stage IIIB/C and IVM1a melanoma (MEL). J Clin Oncol. 2015;33(suppl.15):TPS9094.

19. Kaufman HL, Kohlhapp FJ, Zloza A. Oncolytic viruses: a new class of immunotherapy drugs. Nat Rev Drug Discov. 2015;14:642-62.

20. Prendergast GC, Malachowski WJ, Mondal A, Scherle P, Muller AJ. Indoleamine 2,3-dioxygenase and its therapeutic inhibition in cancer. Int Rev Cell Mol Biol. 2018;336:175-203.

21. Hornyák L, Dobos N, Koncz G, et al. The role of indoleamine-2,3-dioxygenase in cancer development, diagnostics, and therapy. Front Immunol. 2018;9:151.

22. Beatty GL, O'Dwyer PJ, Clark J, et al. Phase I study of the safety, pharmacokinetics (PK), and pharmacodynamics (PD) of the oral inhibitor of indoleamine 2,3-dioxygenase (IDO1) INCB024360 in patients (pts) with advanced malignancies. J Clin Oncol. 2013;31(suppl 15):3025.

23. Gibney GT, Hamid O, Gangadhar TC, et al. Preliminary results from a phase $1 / 2$ study of INCB024360 combined with ipilimumab (ipi) in patients (pts) with melanoma. J Clin Oncol. 2014;32(suppl.15):3010.

24. Mitchell TC, Hamid O, Smith DC, et al. Epacadostat plus pembrolizumab in patients with advanced solid tumors: phase I results from a multicenter, open-label phase I/II trial (ECHO-202/KEYNOTE037). J Clin Oncol. 2018;36:JCO2018789602.

25. Mullard A. IDO takes a blow. Nat Rev Drug Discov. 2018;17:307.

26. Komiya T, Huang CH. Updates in clinical development of Indoleamine 2, 3-dioxygenase inhibitors for human cancers. Front Oncol. 2018;8:423.

27. Soliman HH, Minton SE, Han HS, et al. A phase I study of indoximod in patients with advanced malignancies. Oncotarget. 2016;7:22928.

28. Liu Y, Liang X, Yin X, et al. Blockade of IDOkynurenine-AhR metabolic circuitry abrogates IFN$\gamma$-induced immunologic dormancy of tumor-repopulating cells. Nat Commun. 2017;8:15207.

29. Mizugaki H, Yamamoto N, Murakami H, et al. Phase I dose-finding study of monotherapy with atezolizumab, an engineered immunoglobulin monoclonal antibody targeting PD-L1, in Japanese patients with advanced solid tumors. Inv New Drugs. 2016;34:596-603.

30. National Institute for Health Research. Atezolizumab in combination with cobimetinib for BRAF wild-type metastatic melanoma-first line. http://www.io.nihr.ac.uk/wp-content/uploads/2018/ 05/13681-Atezolizumab-Cobimetinib-for-MelanomaV1.0-APR2018-NON-CONF.pdf. Accessed 21 Oct 2018.

31. Hwu P, Hamid O, Gonzalez R, et al. Preliminary safety and clinical activity of atezolizumab combined with cobimetinib and vemurafenib in BRAF V600-mutant metastatic melanoma. Ann Oncol. 2016;27(suppl.6):379.

32. Sullivan RJ, Gonzalez R, Lewis $\mathrm{KD}$, et al. Atezolizumab (A) + cobimetinib $(\mathrm{C})$ + vemurafenib (V) in BRAFV600-mutant metastatic melanoma (mel): Updated safety and clinical activity. J Clin Oncol. 2017;35(suppl.15):3063.

33. Andrews LP, Marciscano AE, Drake CG, Vignali DAA. LAG3 (CD223) as a cancer immunotherapy target. Immunol Rev. 2017;276:80-96.

34. European Society for Medical Oncology. ESMO 2017 Congress Scientific Meeting Report. https:// oncologypro.esmo.org/content/download/126251/ 2385263/file/ESMO-2017-Congress-Scientific-Meeti ng-Report.pdf. Accessed 30 Dec 2018.

35. Agarwala SS, Moschos SJ, Johnson ML, et al. Efficacy and safety of entinostat (ENT) and pembrolizumab (PEMBRO) in patients with melanoma progressing on or after a PD-1/L1 blocking antibody. J Clin Oncol. 2018;36(suppl 15):9036.

36. Rizvi NA, Loo D, Baughman JE, et al. A phase 1 study of enoblituzumab in combination with pembrolizumab in patients with advanced B7-H3expressing cancers. J Clin Oncol. 2016;34(suppl.15):TPS3104.

37. Holmgaard RB, Wolchok JD, Zamarin D, Allison JP, Munn DH. Indoleamine 2,3-dioxygenase is a critical resistance mechanism in antitumor $\mathrm{T}$ cell immunotherapy targeting CTLA-4. J Exp Med. 2013;210:1389-402.

38. Sivan A, Corrales L, Hubert N, et al. Commensal Bifidobacterium promotes antitumor immunity and facilitates anti-PD-L1 efficacy. Science. 2015;350:1084-9.

39. Wang Y, Ma R, Liu F, Lee SA, Zhang L. Modulation of gut microbiota: a novel paradigm of enhancing the efficacy of programmed death-1 and programmed death ligand-1 blockade therapy. Front Immunol. 2018;9:374. 